\title{
Is Exposure to the Memories of Others a Necessary Precondition for Collaborative Inhibition?
}

\section{Justina Ohaeri Ekeocha}

William Paterson University

ABSTRACT

In recall tasks, pooled individual productivity is generally greater than collaborative productivity, an effect called collaborative inhibition. This effect is believed to be caused by disruption of individual

\section{KEYWORDS}

collaborative recall

collaborative inhibition

group recall

group memory

collaborative remembering organizational strategies in the collaborative context due to exposure to the memories of others. The present study directly tested the exposure explanation. Three-person groups viewed a slide presentation and later recalled the content first as individuals, and subsequently as groups that were either exposed or not exposed to the memories of others. Results show that shielding participants from the contributions of others did not eliminate collaborative inhibition. The need to give more research attention to social factors is discussed.

\section{INTRODUCTION}

Collaborative inhibition (Weldon \& Bellinger, 1997) is a phenomenon where the quantity of information obtained when a group recalls collaboratively is less than the quantity obtained when information they recalled separately is pooled into a nominal group product (see, e.g., Basden \& Basden, 1995; Basden et al., 1997; Clark et al., 1990; Ekeocha \& Brennan 2008; Finlay et al., 2000; Pereira-Pasarin \& Rajaram, 2011; Weldon \& Bellinger, 1997; Weldon et al., 2000; Wissman, 2020; Wright \& Klumpp, 2004; see Harris et al., 2008; Rajaram \& Pereira-Pasarin, 2010, for reviews).

Collaborative inhibition is a robust and ubiquitous effect. Although traditionally studied with word lists, the pattern of results has also been obtained in research that employed other types of study material, including stories (e.g., Ekeocha \& Brennan, 2008; Stephenson et al., 1986;
Weldon \& Bellinger, 1997), key-term definitions (e.g., Wissman, 2020), emotional Stroop tasks (e.g., Zhang et al. 2020), and spatial tasks (e.g., Sjolund et al., 2014). The effect has also been obtained in both face-toface and computer-mediated contexts (e.g., Ekeocha \& Brennan, 2008; Hinds \& Payne, 2016), as well as in same- and mixed-age collaboration contexts (e.g., Whillock et al., 2020).

Weldon and Bellinger (1997) suggested that collaboration disrupts individual organizational strategies, consequently lowering individual productivity in collaborative settings. This strategy disruption hypothe-

Corresponding author: Justina O. Ekeocha, Department of Psychology, William Paterson University, 300 Pompton Road, Wayne, NJ 07470

Email:ekeochaj@wpunj.edu 
sis, currently the dominant explanation for collaborative inhibition (see Basden et al., 1997; Blumen \& Rajaram, 2008; Finlay et al., 2000; Weldon, et al., 2000; Wright \& Klumpp, 2004; Zhang et al. 2020), presents collaborative inhibition as functioning in a manner similar to part-list cuing inhibition, where providing some items from a studied list at recall time inhibits the retrieval of the remaining list items (see Anderson \& Neely, 1996; Basden \& Basden, 1995; Nickerson, 1984; Roediger, 1973; Rundus, 1973, for reviews of part-list cuing). Results from Basden et al. (1997) showed that for multi-category lists, clustering of items by category was greater in individual than in collaborative group recall, suggesting that individuals strategically organize items on the study list in a meaningful way. Further evidence for retrieval interference comes from the fact that when well-integrated, highly organized material (e.g., small categories of items) is used in recall tasks, collaborative groups are sometimes capable of recalling as many category items as nominal groups. This result was attributed to well-organized materials leaving little room for idiosyncratic organization (Basden et al., 1997).

Therefore, Weldon and Bellinger (1997) concluded that reduced productivity in collaborative recall can be attributed to strategy disruption, where exposure to memory items presented by other group members during the collaboration session is believed to interfere with an individual's organizational strategy. When working alone, individuals can utilize their idiosyncratic organizational schemes to efficiently retrieve memorized information. On the other hand, in a collaborative situation, since individual organizational schemes differ, items contributed by one group member might disrupt another's organizational scheme, causing them to deviate from their own retrieval strategies, and making it difficult for them to reconstruct their own knowledge (see also Basden et al., 2002, and Finlay et al., 2000).

However, except for a study by Wright and Klumpp (2004), the claim that collaborative inhibition is due to exposure to the memories of others has not yet been directly tested. Wright and Klumpp had two collaboration contexts where dyads studied four lists of words and then recalled the lists under conditions where they either saw or did not see their partners' contributions. The findings were that dyads in the "see" condition experienced inhibition while those in the "not see" condition did not. Wright and Klumpp concluded that inhibition was due to participants being exposed to the memories of their partners during collaboration.

Note, however, that Wright and Klumpp's (2004) results may have been confounded with methodological issues. In the "not see" condition, each participant had a separate answer sheet, with labels for the four studied categories written on the top. Participants then took turns writing one item at a time on their own answer sheets. However, for the "see "condition, the two participants wrote on the same answer sheet, which also had labels for the four studied categories written across the top. The participants had to pass the sheet back and forth, with each person writing one item per turn. Participants could recall from any of the four categories, but could not repeat any item that was already recalled by their partner. This meant that with each turn a participant had to look across the categories to find what their partner had contributed on their last turn so as not to repeat it. Hence, the process was notably more cumbersome for groups in the "see" condition than for those in the "not see" condition. It could, then, be argued that the lower productivity in the "see" condition may have been due to the process of recall rather than solely to the fact that participants saw one another's recall items.

Therefore, the need remains to clearly establish whether or not exposure to the memories of others is the underlying factor in collaborative inhibition, as there are other potentially influential factors including, to name a few, social facilitation (Zajonc, 1965), where an individual's performance is influenced by the presence of an audience, social anxiety (Eysenck, 1992), which has been shown to negatively affect performance in cognitive tasks (Eysenck et al., 2007, Sarason, 1988), and conformity (Reysen, 2005; Schneider \& Watkins, 1996; Walther et al., 2002).

The goal of the current study, however, was to directly test the effect of exposure to the memories of others on recall productivity. In Experiment 1, the productivity of groups that recalled under exposure and no exposure conditions was tested. In Experiment 2, exposure was manipulated within the collaborative group such that during the group session, one member of the group recalled without exposure while the others recalled with exposure. If the deficit in group productivity is attributable solely to exposure to the memories of others, then the following predictions can be made:

1. The quantitative difference between real group products and nominal group products should be eliminated in contexts that do not involve exposure, in contrast to contexts that involve exposure. Note that a real group product is generated in the context of a group recall session and a nominal group product is created by pooling (nonredundantly) the products of the same number of individuals who recalled separately.

2. The productivity of groups that recall with exposure should be lower than the productivity of groups that recall without exposure.

3. Individuals who recall without exposure should not suffer inhibition, whether they recall alone or in a group context. Therefore, (a) the productivity of individuals when recalling in a no-exposure group context should be comparable to the productivity of the same individuals when recalling alone, (b) the productivity of individuals when recalling in a no-exposure group context should be comparable to the productivity of other individuals who recall alone, and (c), within the same group, an individual who recalls without exposure should recall significantly more than other group members who recall with exposure.

\section{EXPERIMENT 1: COLLABORATIVE VERSUS COLLECTIVE GROUP RECALL}

In Experiment 1, the productivity of groups that recalled collaboratively (with exposure) and groups that recalled collectively (without exposure) was tested. 


\section{Method}

\section{PARTICIPANTS}

One hundred and eight William Paterson University undergraduate students participated in this study for course credit. After signing an informed consent form, participants were randomly assigned to experimental and control groups. Thirty-six participants were run in the collaborative group condition (12 groups). Thirty-six participants were run in the collective group condition (12 groups). Thirty-six participants were run alone in the control condition.

\section{DESIGN}

A mixed design was used in this study. The first variable, type of recall, was tested within subjects: each participant in the experimental conditions was first tested alone (individual recall) and then with two other participants (group recall). The second variable, group recall context, was tested between subjects: groups were tested in either the collaborative context (the exposure context, where participants spoke their memories out loud) or the collective context (the no-exposure context, where participants wrote their memories on index cards). Although it is optimal in a within-subjects design to counterbalance the order of trials, a fixed individual recall first, group recall second order was utilized in this study. In order to directly assess the impact of the collaboration process on individual productivity, it was necessary to first determine individual productivity prior to the group session. Running the group session first would not have allowed the assessment of what and how much a given participant uniquely remembered. However, running the two recall sessions in this fixed order format left Recall Session 2 vulnerable to the potential impacts of temporal distance from the learning phase (negative impact) and re-exposure to some of the stimuli during the first recall session (positive impact). Therefore, the control condition, where participants were tested alone in two consecutive recall sessions was used, both as a comparison group for participants in the collective condition (since there was no exposure in either context), and as a gauge for possible productivity loss or gain in Session 2 due to the use of a fixed repeated recall format in the experimental conditions.

\section{MATERIALS}

Participants viewed a PowerPoint slide presentation of six familiar household scenes: toolbox, bathroom, kitchen, bedroom, closet, and desk (as used in Roediger et al., 2001). There was one slide per scene and each scene contained an average of 24 items, for a total of approximately 144 items). The slides were presented on a 17 in. computer monitor, in slideshow mode.

While studies of collaborative inhibition have traditionally employed word lists, pictures were used in the current study. This was done in order to afford groups optimal opportunity for good performance, based on the finding that pictures are better remembered than words (see Nelson, 1979). Also, as previously stated, when well-integrated, highly organized material (e.g., small categories of items) was used in recall tasks, collaborative groups were sometimes capable of recalling as many category items as nominal groups, with this result attributed to well-organized materials leaving little room for idiosyncratic organization (Basden et al., 1997). The scenes used in the current study represent organized material. See Appendix A for an example scene.

\section{Procedure}

\section{EXPERIMENTAL CONDITION}

The study phase. The three participants in a given experimental group viewed the slide presentation together. They were instructed to pay attention to the items on the slides as they would be asked to recall them later. They were also instructed not to talk to one another during the presentation. Slides were set up to automatically advance at 15 $\mathrm{s}$ intervals. A $10 \mathrm{~s}$ delay was built-in at the beginning of the slide show to allow participants to be settled and focused before the presentation of the first slide. Slides were shown in the same order for all sessions: toolbox, bathroom, kitchen, bedroom, closet, and desk. At the end of the slide show, participants were given a 5 min retention task, where they separately wrote the names of as many countries as they could think of.

Recall Session 1: Pre-group individual recall. Following the retention task, participants were asked to separately recall the study material. Participants were seated in cubicles separated by six feet high dividers, in front of computers with open, blank Microsoft Word documents. A post-it note with "DONE" written on it was placed on each computer desk. Participants were instructed to think back to the slides they had seen and to write down as many of the items as they could remember, in whatever order they chose. There was no time limit imposed on this task. Participants were instructed to stick the "DONE" post-it to their cubicle wall when they were done, but to stay quietly in their seats until called out by the experimenter.

Recall Session 2: Group recall. When all participants were done, they were called out and seated around a rectangular table where they were asked to once again recall the study material, but now as a group. What groups did at this point was dependent on the experimental condition under which the session was run - collaborative or collective. There was no time limit imposed on this task.

Collaborative condition. This condition involved exposure. The three participants in the group spontaneously recalled the items they remembered, using a free-flowing, normal conversational format. Group sessions were tape-recorded.

Collective condition. This condition did not involve exposure. The three participants were seated, spaced out around the table, with a pile of index cards in front of each participant, and a round, deep bowl placed at the center of the table. Participants wrote their recall items on the index cards, one item per card, and placed the cards in the bowl. Participants were instructed not to speak during this session. Participants contributed freely and spontaneously; no turn taking was required.

According to Prediction 3 of this study, individuals who recall in the collective context should be able to maintain their idiosyncratic retrieval strategies and, therefore, not suffer inhibition in the group session. Therefore, their ingroup productivity should be comparable to their individual productivity in Recall Session 1. In order to track individual productivity in the group session, participants were privately labeled 1 , 
2 , or 3 by the experimenter and each participant was given a different color pen: Participant 1 was always given black, Participant 2 was given blue, and Participant 3 was given red. Items recalled by each participant were later listed under their individual labels (Participant 1, 2, or 3) in the group product document.

\section{CONTROL CONDITION}

Thirty-six participants each viewed the slides alone and were tested alone in two consecutive, untimed recall sessions. Since these participants were used as a comparison group for participants in the collective condition, the first recall session was typed and the second session was handwritten, to match the experience of participants in the collective condition. According to Prediction 3 of this study, since there was no exposure in either context, the productivity of individuals in the collective condition (alone and in group) should be comparable to the productivity of individuals who recall alone.

\section{CODING}

The within-subjects manipulation utilized in this study enabled the generation of individual, nominal group, and real group data from the same set of three participants. Nominal group products were created by pooling nonredundant items from the pre-group recall protocols of the three participants in each group. In the end, for each group of three the following data were recorded: (a) the number of items recalled by each participant in Session 1, (b) the number of items in the nominal group product, and (c) the number of items in the real group product from Session 2. Additionally, for groups that were run in the collective condition, the number of items contributed by each member during the group session was also separately noted.

\section{Results}

Analyses were based on the mean number of items recalled. Repeated-measures analyses of variance (ANOVAs) and paired-samples $t$ tests were used for within-subjects analyses while independentsamples $t$ tests were used to make between-subjects comparisons. The a level was set at .05 for all analyses.

\section{REAL GROUP VERSUS NOMINAL GROUP PRODUCTIVITY}

According to Prediction 1, if the deficit in group productivity is attributable solely to exposure to the memories of others, then the quantitative difference between real group products and nominal group products should be eliminated in contexts that do not involve exposure. This means that one should expect nominal group productivity to be higher than group productivity for collaborative groups, but not for collective groups. To test this prediction, a repeated-measures ANOVA was conducted, with group type (real vs. nominal) as the within-subjects variable and group recall context (collaborative vs. collective) as the between-subjects variable. Results showed a significant main effect of group type, $F(1,22)=24.72$, MSE $=77.89, p<.001, \eta_{\rho}^{2}=.53$, where a greater amount of the learned material was found in nominal group products $(M$ $=59.75, S D=13.78)$ than in real group products $(M=47.08, S D=15.49)$. However, there was no significant main effect of group recall context, $F(1$,
22) $=1.60, p=.22$. The pattern of results was similar for collaborative and collective group contexts (see Figure 1). There was also no significant interaction between group type and group recall context, $F(1,22)=3.12$, $p=.09$. These results do not support the exposure hypothesis; nominal group productivity was significantly higher than real group productivity in both the exposure and the no-exposure contexts.

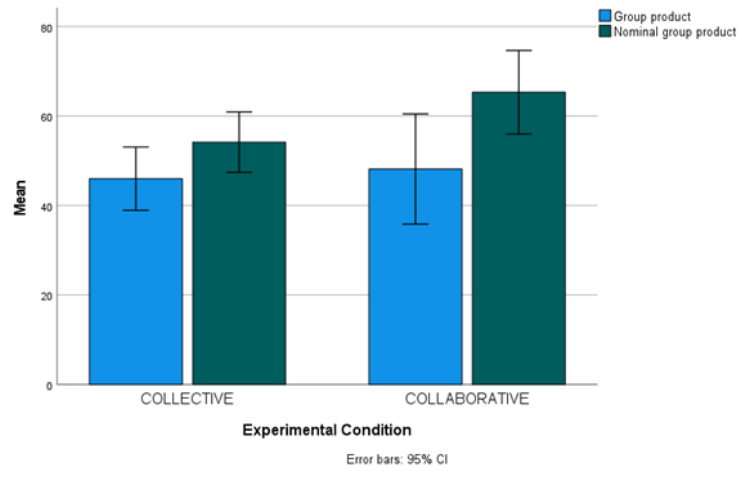

FIGURE 1.

Mean group recall productivity in collaborative and collective contexts.

\section{COLLABORATIVE GROUP VERSUS COLLECTIVE GROUP PRODUCTIVITY}

According to Prediction 2, if the deficit in group productivity is attributable to exposure to the memories of others, then the productivity of groups that recalled in the collaborative (exposure) context should be lower than the productivity of groups that recalled in the collective (no exposure) context. However, an independent-samples $t$ test showed no significant productivity difference between the two group recall contexts, $t(22)=.34, p=.74$. Groups who recalled with exposure recalled about as much $(M=48.17, S D=19.37)$ as those who recalled without exposure $(M=46.00, S D=11.14)$. These results do not support the exposure hypothesis.

\section{INDIVIDUAL PRODUCTIVITY ALONE VERSUS IN GROUP}

According to Prediction 3, if the deficit in individual productivity in the group context is attributable to exposure to the memories of others, then individuals who recall in the collective (no exposure) group context should be able to maintain their idiosyncratic retrieval strategies, and not suffer inhibition. Therefore, the amount of information these individuals contribute to the group product in Session 2 should be comparable to the amount of information they had produced alone in Session 1. Since the productivity of each participant in the collective condition was tracked across the two recall sessions, it was possible to make this comparison. A paired-samples $t$ test comparing individual productivity alone and in group showed a significant difference, $t(35)=3.70, p=001, d=0.66$, where productivity was higher in the individual context $(M=24.94, S D$ =9.40) than in the group context $(M=21.53, S D=7.67$; see Figure 2$)$.

It was also predicted that, if the deficit in individual productivity in the group context is attributable to exposure to the memories of others, then the productivity of individuals who recalled in a no-exposure group 


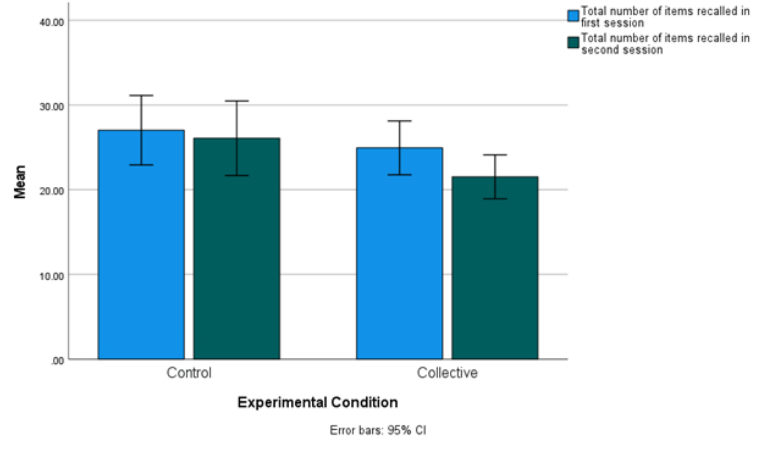

FIGURE 2.

Mean individual recall productivity in the control and collective contexts

context should be comparable to the productivity of individuals who recalled alone. Therefore, the productivity of individuals in the collective condition who first recalled alone and then in group was compared to the productivity of individuals in the control condition who recalled alone twice. Independent-samples $t$ tests showed that while there was no significant productivity difference in recall Session 1 for individuals in the control $(M=27.03, S D=12.12)$ and collective $(M=24.94, S D=9.40)$ conditions, $t(70)=.81, p=.42$, the difference between these two sets of participants in recall Session 2 was marginally significant, $t(70)=1.81, p$ $=.07$, where participants in the control condition recalled more items $(M$ $=26.08, S D=13.01)$ than those in the collective condition $(M=21.53$, $S D=7.67$; see Figure 2).

Furthermore, while for participants in the control condition, there was no significant difference in productivity between Session $1(M=$ 27.03, $S D=12.12)$ and Session $2(M=26.08, S D=13.01), t(35)=1.31$, $p=.20$, this comparison was significant for individuals in the collective condition, where productivity was higher in Session 1 - the individual context $(M=24.94, S D=9.40)$ than in Session 2 - the group context ( $M=21.53, S D=7.67), t(35)=3.70, p=.001, d=0.66$ (see Figure 2). Note that the lack of significant difference in productivity between Recall Sessions 1 and 2 for participants in the control condition suggests no detrimental effect of temporal distance from the learning phase in Session 2. Therefore, the observed significant decrement in productivity in Session 2 for individuals in the collective condition cannot be attributed to temporal distance from the learning phase.

These results do not support the exposure hypothesis because, although participants in the collective condition were not exposed to one another's memory in the group context, they still suffered inhibition.

\section{EXPERIMENT 2}

In Experiment 1, the inherent difference between the collaborative and collective group contexts, that is, free conversation versus silent writing, made the two conditions different beyond the exposure factor and could have influenced the results. Therefore, Experiment 2 further investigated the exposure hypothesis by manipulating exposure only in the collaborative context. During the group session, one member of the group recalled without exposure while the others recalled with exposure. The exposure hypothesis would predict significantly higher productivity for the member who recalled without exposure, in comparison to the members who recalled with exposure.

\section{Method}

\section{PARTICIPANTS}

Sixty-three William Paterson University undergraduate students participated in this study for course credit. Each participant signed an informed consent form. Participants were tested in groups of three, for a total of 21 groups.

\section{MATERIALS AND DESIGN}

Materials were as in Experiment 1. The study utilized a withinsubjects design. Each participant was tested alone and as part of a group.

\section{PROCEDURE}

Participants viewed the PowerPoint presentation together and, after a 5 min retention task, recalled the material in two consecutive sessions, first separately and then as a group. In order to be able to compare individual productivity alone and in group, the performance of each group member was tracked. Each participant was privately labeled Participant 1,2 , or 3 by the experimenter and their products in the individual session, as well as their contributions in the group session, were labeled accordingly.

During the group session, recall was conducted sequentially. Each participant presented, all at once, the items they recalled from the study material, while others listened. The person labeled Participant 1 always recalled first, followed by Participant 2, and finally Participant 3 . Participants were instructed to present everything they recalled even if some of their items had been mentioned by another participant. There was no time limit imposed on this task. When everyone had taken a turn, participants were given the opportunity to present anything else they may have missed during their turn. Group sessions were audio-recorded.

The person of interest in this manipulation was Participant 1. It was predicted that if exposure to the memories of others causes the organizational disruption that leads to low recall productivity, then Participants 1 should not be affected since these participants presented their items first, before hearing the contributions of the other two participants. Participants 1 were expected to be able to maintain the recall strategy that they had utilized in the individual recall session and, therefore, not suffer significant deficit in the group context.

\section{CODING}

As in Experiment 1, nominal group products were created by combining nonredundant items from the three individual recall protocols for each group.

In counting individual contributions to the group product, care was taken to separate what participants uniquely remembered from what they may have gained from hearing other group members. This process was particularly relevant for Participants 2 and 3. For each participant, 
items they contributed during the group session were compared to items they had recalled during the preceding individual session. Any item that was contributed during the group session, but that was not in the initial individual recall product, was identified. The session transcript was then reviewed to see if the item had been presented by another participant during the group session. If yes, the item was assumed to have been "borrowed" from the other group member and, therefore, was not counted for the participant. However, if no one else had presented the item during the group session, then the item was regarded as spontaneous new recall, and included in the participant's count.

\section{Results}

Paired-samples $t$ tests were used for within-subject analyses and oneway between-subjects ANOVAs and independent-samples $t$ tests were used for between-subjects analyses. a was set to .05 for all analyses.

\section{GROUP PRODUCTIVITY VERSUS NOMINAL GROUP PRODUCTIVITY}

A paired-samples $t$ test comparing nominal group and real group productivity yielded a significant result, $t(62)=13.02, p<.001, d=1.64$. Consistent with previous findings, nominal group productivity $(M=$ $72.38, S D=15.87$ ) was significantly greater than real group productivity $(M=53.38, S D=14.93)$.

\section{INDIVIDUAL PRODUCTIVITY ALONE VERSUS IN GROUP}

It was predicted that if exposure to the memories of others is responsible for reduced individual recall in the collaborative context, then Participants 1, who presented their recall items before hearing the contributions of other group members, should be able to maintain the same level of productivity in the group context that they had achieved in the individual session. However, paired-samples $t$ tests showed a significant difference in the individual and ingroup productivity of all three participants, with productivity being higher in the individual than in the group context: Participant $1, t(20)=5.40, p<.001, d=1.18$; Participant $2, t(20)$ $=6.40, p<.001, d=1.40$; and Participant $3, t(20)=4.84, p<.001, d=$ 1.01. See Table 1 for all means.

Furthermore, a one-way ANOVA revealed no significant difference in the amount of information contributed by Participant $1(M=18.60$, $S D=6.99)$, Participant $2(M=23.80, S D=8.35)$, and Participant $3(M$ $=20.50, S D=8.82$ ) during the group session, $F(2,60)=1.26, p=.29$. It is worth mentioning, though, that productivity in the group session was lowest for Participant 1 . Note that the results for these analyses did not change even when borrowed items were included in the calculations.

\begin{tabular}{|c|c|c|c|}
\hline \multicolumn{4}{|c|}{$\begin{array}{l}\text { TABLE } 1 . \\
\text { Mean Recall Productivity for Participants 1, 2, and 3, in the Indi- } \\
\text { vidual and Group Sessions }\end{array}$} \\
\hline & Participant 1 & Participant 2 & Participant 3 \\
\hline \multicolumn{4}{|c|}{ Individual session } \\
\hline$M$ & 31.80 & 35.80 & 31.80 \\
\hline$S D$ & 9.97 & 11.45 & 13.30 \\
\hline \multicolumn{4}{|l|}{ Group session } \\
\hline$M$ & 18.60 & 23.80 & 20.50 \\
\hline$S D$ & 6.99 & 8.35 & 8.82 \\
\hline
\end{tabular}

The mean number of borrowed items was $2.43(S D=2.83)$. Therefore, the results of Experiment 2 show that Participant 1 who recalled without exposure was as inhibited during the group session as were Participants 2 and 3 who recalled with exposure.

To summarize, the results of both Experiments 1 and 2 do not support the exposure hypothesis. Not seeing the contributions of others did not provide any buffer against collaborative inhibition.

\section{DISCUSSION}

When a group of individuals recalls a shared experience, the amount of information they recall as a collaborative group is generally less than the amount obtained by pooling the information they recall separately, an effect termed collaborative inhibition by Weldon and Bellinger (1997). It has since been argued that collaborative inhibition is attributable to strategy disruption, where it is believed that exposure to the memories of others during collaboration interferes with an individual's ability to maintain their own idiosyncratic retrieval strategy and, therefore, makes it difficult for them to reconstruct their own memories (Weldon \& Bellinger, 1997; Weldon et al., 2000; Wright \& Klumpp, 2004). The present study tested this exposure hypothesis based on the rationale that if the deficit in group productivity is attributable to exposure to the memories of others, then (a) the quantitative difference between real groups and nominal groups should be eliminated in contexts that do not involve exposure, (b) the productivity of groups that recalled with exposure should be lower than the productivity of groups that recalled without exposure, and (c) the ingroup productivity of individuals who recalled without exposure should be comparable to their productivity when they recalled alone, as well as to the productivity of other individuals who recalled alone.

The results of the present study did not support the above predictions. In Experiment 1, elimination of exposure did not eliminate the productivity difference favoring nominal group products over real group products. Group productivity was not higher for groups who recalled collectively (without exposure), when compared to groups that recalled collaboratively (with exposure). Also, while productivity was comparable for individuals in the control and collective conditions in Session 1, where both groups recalled alone, productivity for the two groups differed in Session 2, where the control group once again recalled alone and the collective group recalled in a group context, with participants in the collective condition recalling less than their control counterparts. In Experiment 2, Participants 1, who had presented their recall items before hearing the memories of other group members, contributed fewer items in the group session than they had in their individual session. There was also no difference in the amount of information they contributed in group compared to Participants 2 and 3 who had recalled under the exposure condition. Therefore, it appears that exposure to the memories of others is not a necessary precondition for collaborative inhibition.

One fact that must be kept in mind as the search for the critical factor in collaborative inhibition continues is that collaborative recall is a socio-cognitive activity. Therefore, the investigation into causative factors must not focus solely on the cognitive component, but must also 
include the social, as social factors may act as precursors to the cognitive inhibition experienced in collaborative contexts. For example, research in social psychology has long shown the social facilitation effect (Zajonc, 1965), where an individual's performance is influenced by the presence of an audience. In the collaborative recall context, group members can be considered an audience whose presence could impact the performance of an individual.

There is also substantial research linking anxiety to impaired cognitive performance (see Eysenck, 1992, for a review) where the experience of anxiety leads to a situation where a portion of the attentional resources that should be dedicated to the performance of a cognitive task is allocated to managing task-irrelevant thoughts generally related to selfpreoccupation (Eysenck et al., 2007, Sarason, 1988). It is plausible that group recall contexts engender heightened feelings of self-consciousness and apprehension that negatively impact individual productivity. When someone is working privately, thought processes that are usually engendered by the presence of other people are not activated. Therefore, much of the person's attention would be devoted to the task. A group context, on the other hand, heightens a person's awareness of themselves as a social object and might, therefore, be more likely to lead to self-focused attention. Managing self-focused thoughts, as well as the emotions associated with them, could reduce the amount of attention available for the central task and interfere with a person's ability to perform well.

Lastly, a link has also been established between conformity and memory performance (e.g., Reysen, 2005; Schneider \& Watkins, 1996; Walther et al., 2002), where the memory performance of individuals is influenced by the actions of other group members.

In conclusion, since collaborative recall occurs in a social context, it is imperative that research into collaborative inhibition seeks to reveal how social and cognitive factors may interact to inhibit individual productivity in the collaborative context. One methodological addition to be considered in future studies would be the inclusion of a measure of arousal. This would enable the assessment of arousal levels during recall in the individual and group contexts, and might shed clearer light on the cognitive consequences of collaborative recall contexts. Another methodological consideration, particularly with regard to the experimental design utilized in the current study, would be to equate, as much as possible, the recall modality in the two group contexts. The inherent difference, beyond exposure, between the collaborative and collective groups in Experiment 1, where one group session was in the context of normal, free flowing, interactive oral conversation and the other was in the context of silent writing, is duly noted. A future effort might look into utilizing the same collaboration format for the two recall contexts. This could be accomplished by means of a computer mediated communication platform.

\section{ACKNOWLEDGEMENTS}

I would like to thank the following individuals for their assistance in the completion of this research project: Gyna Meneses, Caroline Flowers, Jasmine Rodriguez, Sara Fleckenstein, Sapphire Toussaint, Anthony Gonzalez, Jeannina Ruiz, Zulma Farrell, Kristen Urena, Neha Patel, Breeasja Craton, and Tiffany Jenkins.

\section{REFERENCES}

Anderson, M. C., \& Neely, J. H. (1996). Interference and inhibition in memory retrieval. In E. Bjork, B. Ligon, \& A. Robert (Eds.), Memory (pp. 237-313). Academic Press.

Basden, D. R., \& Basden, B. H. (1995). Some tests of the strategy disruption interpretation of part-list cuing inhibition. Journal of Experimental Psychology: Learning, Memory, and Cognition, 21, 1656-1669. doi: 10.1037/0278-7393.21.6.1656 المالسلبل

Basden, B. H., Basden, D. R., \& Henry, S. (2000). Costs and benefits of collaborative remembering. Applied Cognitive Psychology, 14, 497-507. doi: 10.1002/1099-0720(200011/12)14:6<497::AIDACP665>3.0.CO;2-4 لسلسلس

Basden, B. H., Basden, D. R., \& Stephens, J. P. (2002). Part-set cuing of order information in recall tests. Journal of Memory and Language, 47, 517-529. doi: 10.1016/S0749-596X(02)00016-5 迤

Basden, B. H., Basden, D. R., Bryner, S., \& Thomas, R. L. (1997). A comparison of group and individual remembering: Does collaboration disrupt retrieval strategies? Journal of Experimental Psychology: Learning, Memory, and Cognition, 23, 1176-1189. doi: 10.1037/0278-7393.23.5.1176 المالمالس

Blumen, H. M., \& Rajaram, S. (2008). Influence of re-exposure and retrieval disruption during group collaboration on later individual

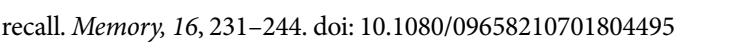

Clark, N. K., Stephenson, G. M., \& Kniveton, B. H. (1990). Social remembering: Quantitative aspects of individual and collaborative remembering by police officers and students. British Journal of Psychology, 81, 73-94. doi: 10.1111/j.2044-8295.1990.tb02347.x المالسلسلس of Ekeocha, J. O. \& Brennan, S.E. (2008). Collaborative recall in face-to-face and electronic groups. Memory, 16, 245-261. doi: 10.1080/09658210701807480 سلس إلس

Eysenck, M. W. (1992). Anxiety: The cognitive perspective. Erlbaum Eysenck, M. W., Derakshan, N., Santos, R., \& Calvo, M.G. (2007). Anxiety and cognitive performance: Attentional control theory. Emotion, 7, 336-353. doi: 10.1037/1528-3542.7.2.336 الس

Finlay, F., Hitch, G. J., \& Meudell, P. R. (2000). Mutual inhibition in collaborative recall: Evidence for a retrieval-based account. Journal of Experimental Psychology: Learning, Memory, \& Cognition, 26, 1556-1567. doi: 10.1037/0278-7393.26.6.1556 المالسلس

Harris, C. B., Paterson, H. M., \& Kemp, R. I. (2008). Collaborative recall and collective memory: What happens when we remember together? Memory, 16, 213-230. doi: 10.1080/09658210701811862 السلسلسلة

Hinds, J. M. \& Payne, S. J. (2016). Collaborative inhibition and semantic recall: Improving collaboration through computer-mediated communication. Applied Cognitive Psychology, 30, 554-565. doi: 10.1002/acp.3228 المالسلس

Nelson, D. L. (1979). Remembering pictures and words: Appearance, significance, and name. In L. S. Cermak \& E I. M. Craik (Eds.), Levels of processing in human memory (pp. 45-76). Erlbaum.

Nickerson, R. S. (1984). Retrieval inhibition from part-set cuing: A persistent enigma in memory research. Memory \& Cognition, 12,

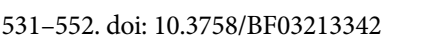

Pereira-Pasarin, L. P., \& Rajaram, S. (2011). Study repetition and di- 
vided attention: Effects of encoding manipulations on collaborative inhibition in group recall. Memory \& Cognition, 39, 968-976. doi: 10.3758/s13421-011-0087-y yلسلسلس

Rajaram, S. \& Pereira-Pasarin, L. P. (2010) Collaborative memory: Cognitive research and theory. Perspectives on Psychological Science, 5, 649-663. doi: 10.1177/1745691610388763 سلس الس الس

Reysen, M. B. (2005). The effects of conformity on recognition judgments. Memory, 13, 87-94. doi: 10.1080/09658210344000602 الس

Roediger, H. L., III, (1973). Inhibition in recall from cueing with recall targets. Journal of Verbal Learning and Verbal Behavior, 12, 644-657.

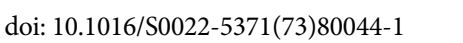

Roediger, H. L., Meade, M. L., \& Bergman, E. T. (2001). Social contagion of memory. Psychonomic Bulletin \& Review, 8, 365-371. doi: 10.3758/BF03196174 السلسلسلئل

Rundus, D. (1973). Negative effects of using list items as recall cues. Journal of Verbal Learning and Verbal Behavior, 12, 43-50. doi: 10.1016/S0022-5371(73)80059-3 السلسلس

Sarason, I. G. (1988). Anxiety, self-preoccupation, and attention. Anxiety Research, 1, 3-7. doi: 10.1080/10615808808248215 الس السلس

Schneider, D. M. \& Watkins, M. J. (1996). Response conformity in recognition testing. Psychonomic Bulletin \& Review, 3, 481-485. doi: 10.3758/BF03214550 الس

Sjolund, L. A., Erdman, M., \& Kelly, J. W. (2014). Collaborative inhibition in spatial memory retrieval. Memory and Cognition, 42,

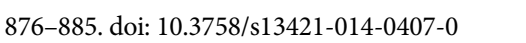

Stephenson, G. M., Clark, N. K., \& Wade, G. S. (1986). Meetings make evidence? An experimental study of collaborative and individual recall of imulated police interrogation. Journal of Personality and Social Psychology, 50, 1113-1122. doi: 10.1037/0022-3514.50.6.1113 الس السلس
Walther, E., Bless, H., Strack, F., Rackstraw, P., Wagner, D., \& Werth, L.(2002). Conformity effects in memory as a function of group size, dissenters and uncertainty. Applied Cognitive Psychology, 16, 793-810. doi: 10.1002/acp.828 سلس الس

Weldon, M. S., \& Bellinger, K. D. (1997). Collective memory: Collaborative and individual processes in remembering. Journal of Experimental Psychology: Learning, Memory, and Cognition, 23, 1160-1175. doi: 10.1037/0278-7393.23.5.1160 الس السلسلس

Weldon, M. S., Blair, C., \& Huebsch, P. D. (2000). Group remembering: Does social loafing underlie collaborative inhibition? Journal of Experimental Psychology: Learning, Memory, and Cognition, 26, 1568-1577. doi: 10.1037/0278-7393.26.6.1568

Whillock, S. R., Meade, M. L., Hutchison, K. A., \& Tsosie, M. D. (2020). Collaborative inhibition in same-age and mixed-age dyads. Psychology and Aging, 35, 963-973. doi: 10.1037/pag0000490 المالسلس Wissman, K. T. (2020). Investigation of collaborative inhibition for key-term definitions. Applied Cognitive Psychology, 34, 182-193. doi:

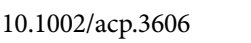

Wright, D. B., \& Klumpp, A. (2004). Collaborative inhibition is due to the product, not the process, of recalling in groups. Psychonomic Bulletin \& Review, 11, 1080-1083. doi: 10.3758/BF03196740 لسلس الس الس

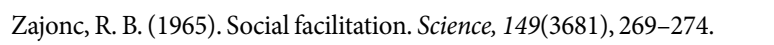
Zhang, H., Zhang, X., Liu, X., Yang, H., \& Shi, J. (2020). Inhibitory process of collaborative inhibition: Assessment using an emotional Stroop task. Psychological Reports, 123, 300-324. doi:

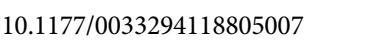




\section{APPENDIX}

Sample Slide: The “Toolbox" scene.

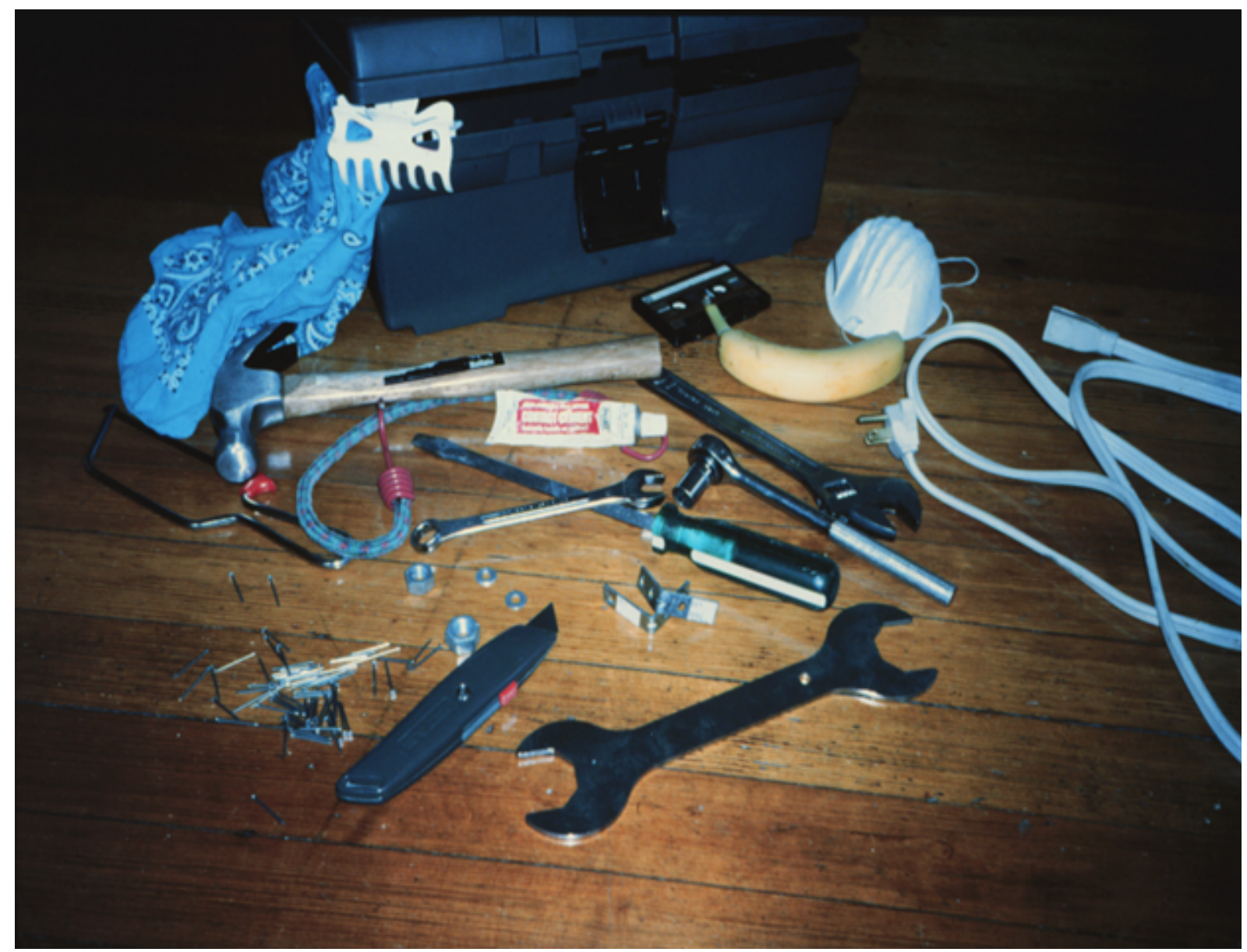

